И.В. Ставцева

Южно-Уральский государственный университет (НИУ), Челябинск, Россия
Получена: 28.03.2016

Принята: 05.04.2016

Опубликована: 30.06.2016

\title{
Е.П. Ерохина
}

Челябинский государственный университет, Челябинск, Россия

\section{МОДЕЛИРОВАНИЕ ФОРМИРОВАНИЯ ИНОЯЗЫЧНОЙ КОММУНИКАТИВНОЙ КОМПЕТЕНЦИИ СОВРЕМЕННОГО СТУДЕНТА-ЛИНГВИСТА}

\begin{abstract}
Рассматривается иноязычная коммуникативная компетенция как обязательный результат профессионального лингвистического образования. Используя метод анализа научной литературы, авторы демонстрируют ее сущность, особенности и компонентный состав. Основное внимание уделено описанию авторской модели формирования данной компетенции посредством ролевой игры, которая рассматривается как эффективный метод, способствующий выполнению важнейших методических задач: созданию психологической готовности обучающегося к межличностному общению, тренировке в выборе нужного речевого варианта, что является подготовкой к спонтанной, ситуативной речи в целом. Предлагаемая модель формирования иноязычной коммуникативной компетенции посредством ролевой игры разработана для студентов бакалавриата направления «Лингвистика», обучающихся по федеральному государственному образовательному стандарту высшего образования поколения 3+ (ФГОС ВО). В качестве основы для создания модели авторы выбирают учебно-методический комплекс, представленный в рекомендованном Министерством образования РФ для студентов высших учебных заведений учебнике «Практический курс английского языка: 3 курс» под редакцией В.Д. Аракина. Анализ ролевых игр, предлагаемых в данном учебнике, показывает возможности для их переработки с целью поэтапного, осознанного формирования иноязычной коммуникативной компетенции. При этом на каждом этапе формируется отдельный компонент компетенции, а осознанность достигается благодаря детальной проработке сюжета и ролей самой игры, а также постепенной реализации гибкого управления учебным процессом. В результате авторы разрабатывают модель, включающую в себя три взаимосвязанных компонента: 1) регулятивный (государственное регулирование образовательного процесса); 2) сущностный (состав иноязычной коммуникативной компетенции); 3) формирующий (поэтапный переход от жесткого контроля к полностью гибкому управлению).

Ключевые слова: иноязычная коммуникативная компетенция, ролевая игра, бакалавр направления «Лингвистика», ФГОС ВО, моделирование.
\end{abstract}


I.V. Stavtseva

South Ural State University (National Research University), Chelyabinsk, Russia
Received: 28.03.2016

Accepted: 05.04.2016

Published: 30.06 .2016

\section{E.P. Erokhina}

Chelyabinsk State University, Chelyabinsk, Russia

\section{MODELING OF LINGUISTICS STUDENT'S COMMUNICATIVE COMPETENCE DEVELOPMENT}

The paper focuses on foreign language communicative competence as an essential result of professional education in linguistics. The references' analysis shows the peculiarities and the structure of the given competence. Furthermore, the paper deals with the description of the authors' model of student's communicative competence development by means of role playing viewed as an efficient method that helps to implement important methodological tasks, i.e. to lower the affective filter, to make the students ready for interpersonal communication and to train the preferred language patterns required to speak fluently according to the certain situation. Thus, role playing creates the prerequisites for spontaneous speech. The model described represents the process of undergraduate linguistics education based on the latest Federal public educational standard of higher education in Russia. The authors build their model upon the textbook recommended by the Russian Ministry of Education for the university students "Practical course of the English language: for the third year students" edited by V.D. Arakin. Having analyzed the role plays represented in the textbook, the authors find the possibility of their redesign to achieve stage-by-stage conscious communicative competence development (every stage develops a certain communicative competence component while a detailed role play and overall process organization raises students' consciousness). As a result the authors make a model that includes 3 interrelated components: 1) regulating (corresponding to the Russian educational state standards); 2) essential (corresponding to the foreign language communicative competence structure); 3 ) formative (corresponding to development through stage-by-stage transition from strict supervision to flexible teaching management).

Keywords: foreign language communicative competence, role playing, undergraduate in linguistics, Russian federal public educational standard of higher education, modeling.

Уже довольно давно Россия стала одной из развитых стран, шагающих в ногу со временем, где роль лингвистического образования стоит далеко не на последнем месте. Это связано в первую очередь с формированием более совершенной культуры международных взаимоотношений, а также актуальностью упрочнения связей между странами и народами. Так, межкультурная коммуникация является неотъемлемой частью жизни почти каждого современного человека, который хочет не просто обладать знаниями иностранного языка как показателем его общего интеллектуального развития, но использовать иностранный язык для возможности оставаться конкурентоспособным на рынке труда. В связи с усилением мобильности людей и их мотивации к изучению иностранных языков происходит выдвижение иностранных языков в ряд приоритетных коммуникативных образовательных дисциплин. Обладая большим потенциалом, иноязычное лингвистическое образование помимо решения задач развития личности и ее профессионализации является ресурсом непосредственного формирования коммуникативных умений и навыков иноязычной коммуникативной компетенции. 
Для начала стоит понять, что же такое «иноязычная коммуникативная компетенция»? На наш взгляд, наиболее точно и емко формулирует ее определение И.А. Зимняя, утверждая, что иноязычная коммуникативная компетенция это сформированная способность человека выступать в качестве субъекта коммуникации [1]. Однако анализ ее внутренней структуры, выполненный такими учеными, как Д.Х. Хаймс, Я. ван Эк, М.З. Биболетова, В.В. Сафонова, Л.Ф. Бахман, позволяет говорить о ее сложности и неоднозначности [2-8]. Единственное, в чем данные авторы полностью соглашаются между собой, - это многокомпонентность иноязычной коммуникативной компетенции. Следует отметить, что большинство ученых выделяют в иноязычной коммуникативной компетенции с различной степенью вариации такие составляющие, как языковая / лингвистическая, социокультурная, социолингвистическая, прагматическая, дискурсивная / дискурсная, речемыслительная / речевая и стратегическая компетенции.

Доказательством того, что иноязычная коммуникативная компетенция является неотъемлемой составляющей современного лингвистического образования, является тот факт, что все компоненты данной компетенции находят свое отражение в современном государственном стандарте высшего образования для студентов-лингвистов ФГОС ВО [9].

Опираясь на все вышеизложенное, можно с уверенностью утверждать: иноязычная коммуникативная компетенция является основой профессиональной подготовки студентов-бакалавров лингвистического направления в вузе. Соответственно, актуальными становятся вопросы разработки эффективных и адекватных методов формирования данной компетенции во всей целостности ее компонентов. В своем исследовательском поиске таких методов мы обращаемся к методу ролевой игры, зарекомендовавшему себя в традиционной методике преподавания иностранных языков.

Само понятие «игра» часто ассоциируется с детством, а значит, с чемто ребяческим, развлекательным и лишенным глубокого смысла. Однако не стоит недооценивать роль игр, так как они, полностью погружая играющего в новую реальность, способны дополнить и украсить жизнь не только подрастающего поколения, но и взрослых людей.

Обучающие возможности использования игр известны давно, многие преподаватели используют игры на своих занятиях и отмечают их положительный эффект. Существует такой термин, как «учебная игра» - особо организованное задание, требующее эмоциональных и интеллектуальных затрат [10]. Как утверждает Е.Н. Соловова, такие игры представляют собой небольшую ситуацию со своим сюжетом и участниками, которым необходимо достичь специфической цели в конкретной ситуации общения [11]. Игра на занятии, будь то урок в школе или занятия в университете, способствует выполнению важнейших методических задач: созданию психологической готовности обучающегося к межличностному общению, тренировке в выборе нужного речевого варианта, что является 
подготовкой к спонтанной, ситуативной речи в целом. В данном случае изрядная доля психологического стресса и ошибкобоязни снимается тем фактом, что обучающийся как бы прячется за маской кого-то другого, «играет» свою роль, а не выполняет ее в реальной жизни.

Тем не менее следует отметить, что процесс использования и польза игры недостаточно изучены в рамках компетентностного подхода и постоянно изменяющихся требований в области языкового образования, ситуации, вызванной образовательным кризисом. А ведь именно игра может легко усилить познавательный интерес будущих выпускников, облегчить процесс изучения иностранного языка, а также вывести профессиональное мастерство преподавателя на уровень современных технологий. Игры обладают обучающими, воспитательными, развлекательными, коммуникативными, релаксационными и другими важнейшими для продуктивного изучения иностранного языка функциями.

Дело в том, что многие взрослые люди (а студенты вуза являются таковыми) настороженно относятся к игре на занятиях иностранным языком и далеко не всегда охотно откликаются на данную форму работы. Они ошибочно полагают, что знакомые им монотонные и подчас однотипные упражнения на отработку навыков перевода и грамматики быстрее приведут их к желаемой цели. Многие просто испытывают стеснение, им кажется постыдным и несерьезным участвовать в играх, особенно если они предполагают выход за рамки их действительного социального статуса и привычного контекста деятельности.

В связи с этим огромное значение имеют участие преподавателя в игровом процессе и его умение организовать этот процесс. Преподаватель должен быть полностью уверен в пользе игры и актуальности ее использования в конкретной педагогической ситуации. Однако на данный момент ролевая игра упрочняет свои позиции среди игр, используемых на занятиях иностранным языком, так как имитирует ситуацию реального общения.

Согласно А.А. Леонтьеву ролевая игра особо чувствительна к сфере деятельности людей и отношений между ними, а ее содержанием непосредственно является эта сфера деятельности [12]. В ролевой игре происходит существенная перестройка поведения обучающегося, оно меняется на произвольное. Такая модель поведения снимает часть психологического напряжения, которое сопровождает обычный ответ. Студент чувствует себя более раскрепощенно и свободно, высказывая свою точку зрения от «чужого» лица. Этим и объясняется популярность ролевых игр среди преподавателей и студентов. Ролевые игры являются учебной моделью межличностного группового общения, специфической организационной формой обучения устно-речевому общению, легко вписываются в ход занятий, и, что немаловажно, приносят обучаемым огромное удовольствие. С точки зрения студентов, ролевая игра - это игровая деятельность, в процессе которой они выступают в определенных ролях.

Принимая во внимание приведенные выше характеристики ролевой игры как методического приема, мы разработали модель формирования иноязычной 
коммуникативной компетенции бакалавров лингвистического направления, обучающихся по федеральному государственному образовательному стандарту высшего образования поколения 3+ (ФГОС ВО). Представленная на рисунке модель включает в себя три компонента:

1) регулятивный (государственное регулирование образовательного процесса);

2) сущностный (состав иноязычной коммуникативной компетенции);

3) формирующий (поэтапный переход от жесткого контроля к полностью гибкому управлению).

Регулятивный и сущностный компоненты соотносят компетенции ФГОС ВО по направлению подготовки 45.03.02 «Лингвистика» (уровень бакалавриата) со структурную-сущностной многокомпонентностью иноязычной коммуникативной компетенции. В свою очередь, формирующий компонент представляет структуру работы по формированию данной компетенции, реализуемой через 8 этапов (8 ролевых игр), направленных на формирование составляющих иноязычной коммуникативной компетенции с переходом от жесткого к гибкому управлению образовательным процессом.

Данный переход осуществляется для достижения синергии технологии и творчества [13] в рамках широкого понимания приема ролевой игры как драматизации или игрового моделирования (см. Англо-русский терминологический справочник по методике преподавания иностранных языков И.Л. Колесниковой, О.А. Долгиной [14]), позволяющего постепенно передать управление и организацию ролевой игры в руки студентов. В таком случае игра стимулирует симулятивное, подражательное общение, максимально приближает студентов к реальной коммуникативной ситуации и подключает все компоненты иноязычной коммуникативной компетенции.

В качестве основы для разработки игр мы выбрали рекомендованный Министерством образования РФ для студентов высших учебных заведений учебник «Практический курс английского языка: 3 курс» под редакцией В.Д. Аракина [15]. Проанализировав игры, представленные в данном учебнике, мы выявили их недостатки для всестороннего формирования иноязычной коммуникативной компетенции. Несмотря на разную тематику, все ролевые игры, за исключением одной игры из шестого раздела, однотипны. Кроме того, не понятны основания, почему игра из шестого раздела резко отличается по форме и структуре от игр остальных разделов, а также, по какому принципу за одними играми следуют рекомендации по их проведению и завершению (notes), а остальные игры просто обрываются вместе с описанием последней роли. В данном случае иноязычная коммуникативная компетенция не может быть сформирована должным образом, так как в каждом уроке, кроме шестого, идет упор на лингвистический компонент иноязычной коммуникативной компетенции, а остальные компоненты либо задействованы слабо, либо не задействованы вообще. 


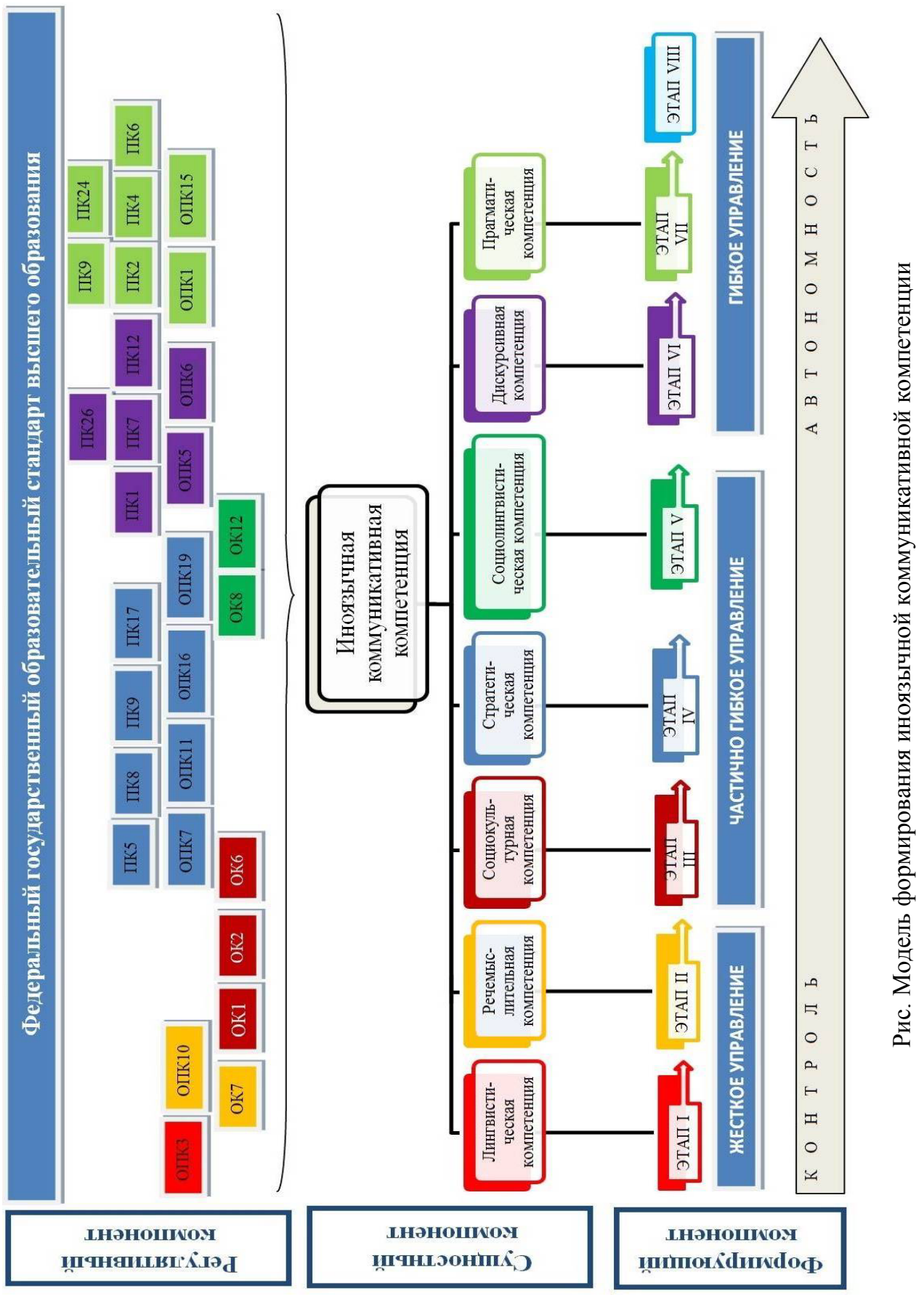


В рамках разработанной модели мы предлагаем наш вариант поэтапного формирования иноязычной коммуникативной компетенции на занятиях иностранным языком, основой которого являются игры, представленные в учебнике В.Д. Аракина. Для успешного формирования данной компетенции мы вносим в уже предложенные автором учебника ролевые игры следующие изменения:

1. В каждой игре внимание фокусируется на отдельной компетенции из состава иноязычной коммуникативной. Сделано это для того, чтобы формирование нужной нам компетенции происходило поэтапно и осознанно для студентов.

2. Игры и этапы располагаются в определенном порядке, чтобы создать плавный переход от жесткого управления к гибкому.

Сохраняется тематическое наполнение каждой ролевой игры в соответствии с рабочей программой по дисциплине «Практический курс английского языка», но форма, цели и задачи игр изменены.

В качестве примера ниже представлена одна из разработанных ролевых игр, предложенная студентам на пятом этапе в процессе формирования социокультурной компетенции:

\section{Situation:}

Topic: «School»

Teachers from all over the world come to the International Teaching Conference. They are gathered to discuss the currently important topic - «The use of modern information technologies in educational process». The purpose of the conference is an exchange of views and experience in this direction.

\section{Roles:}

Adriano, Brazil. Sees the bright future in using modern information technologies in educational process, but fragile financial standing of Brazil does not allow to buy computers and the other necessary equipment, and to modernize classes.

Nadzomi, Japan. Accepts the usage of modern information technologies like something habitual and inherent. Tries to watch all the novelties in this sphere and uses interactive whiteboard, personal computer and the other gadgets actively to make lessons brighter, more interesting and informative.

Maria, Russia. Treats the usage of modern information technologies during the studies with some caution, but tries to keep up with times and uses them once in a while. Thinks that modern technologies cannot replace broad possibilities of traditional methods of teaching.

Jane, Britain. Treats modern technologies in education completely negatively. Thinks that all this new fashioned, electronic things can only distract pupils from the process of studding.

\section{Task:}

Discuss the stated subject. 


\section{Comments:}

1. Semi-flexible control mode is used and share opinions with the colleagues.

2. Focus is made on the sociocultural component of the foreign communicative competence.

Обязательным условием проведения данной игры является создание условной ситуации, типичной для современного мира, - ситуации проведения международной конференции, на которой учителя из разных стран обсуждают способы использования информационных технологий в образовании. Для студентов участие в подобной игре предполагает серьезную подготовку, анализ образовательной ситуации в стране, которую они выбирают. Следует отметить, что роли, предлагаемые преподавателем, являются примерными. На данном этапе формирования иноязычной коммуникативной компетенции задача преподавателя поощрить самостоятельный аргументированный выбор ролей и стран, предложить пофантазировать над видоизменением темы, чтобы она была близка студентам. Важно, чтобы ролевая игра соотносилась с профилем подготовки лингвистов. Предложенная игра создавалась для лингводидактического профиля с ориентацией на тему пятого раздела учебника В.Д. Аракина. Однако переводческий или исследовательский профиль целесообразно ориентировать на изменение ситуации и ролей с сохранением самих условий условно межкультурного диалога. Та же конференция может видоизмениться в переводческую или конференцию по теоретической и прикладной лингвистике в зависимости от профиля подготовки конкретной группы студентов, а также от их собственного выбора.

В заключение хочется сказать, что ролевая игра является, по нашему мнению, оптимальной базой для формирования иноязычной коммуникативной компетенции у студентов-лингвистов, обладающей к тому же множеством преимуществ. Обращение к ролевым играм в контексте формирования компонентов иноязычной коммуникативной компетенции позволит и преподавателям, и студентам по-новому взглянуть на учебный процесс, а также значительно быстрее достигнуть поставленных целей.

\section{Список литературы}

1. Зимняя И.А. Компетенция и компетентностность в рамках компетентностного подхода в образовании // Иностранные языки в школе. - 2012. - № 6. - С. 25-27.

2. Биболетова М.3., Трубанева Н.Н. Программа курса английского языка «Еnjoy English» для учащихся 2-9 классов общеобразовательных учреждений России. - М.: Титул, 2006.

3. Сафонова В.В. Социокультурный подход к обучению иностранным языкам как специальности: автореф. дис. ... д-ра пед. наук. - М., 1993. - 47 с.

4. Сафонова В.В. Коммуникативная компетенция: современные подходы к многоуровневому описанию в методических целях. - М.: Изд-во НИЦ «Еврошкола», 2004. 
5. Hymes D.H. On Communicative Competence // Sociolinguistics. Selected Readings. - Harmondsworth: Penguin, 1972. - P. 269-293.

6. Bachman L.F. Fundamental Considerations in Language Testing. - Oxford: OUP, 1990. - $408 \mathrm{p}$.

7. Van Ek J. Objectives for foreign language learning. Vol.2: Levels. - Strasbourg: Council of Europe, 1987. - 99 p.

8. Гейхман Л.К. Интерактивное обучение общению (общепедагогический подход): дис. ... д-ра пед. наук: 13.00.02. - Екатеринбург, 2003. - 426 с.

9. Федеральный государственный образовательный стандарт высшего образования по направлению подготовки 45.03.02 «Лингвистика» (уровень бакалавриата) [Электронный ресурс]. - URL: http://www.mshu.edu.ru/files/UMU/standarts/45.03.02_ lingvis-tika.pdf (дата обращения: 14.10.2015).

10. Шевц И.А. Ролевые игры как средство повышения эффективности обучения иностранному языку // Экономические, юридические и социокультурные аспекты развития регионов. - Челябинск: Изд-во ЧИЭП им. М.В. Ладошина, 2008. - С. 264-272.

11. Соловова Е.Н. Методика обучения иностранным языкам: базовый курс лекций: пособие для студентов пед. вузов и учителей. - М.: Просвещение, 2005. - 239 с.

12. Леонтьев А.А. Педагогическое общение. - М.: Просвещение, 1980 - 214 с.

13. Гейхман Л.К., Ставцева И.В. Инновационное образование: синергия технологии и творчества // Коммуникация в поликодовом пространстве: лингвокультурологические, дидактические, ценностные аспекты: материалы междунар. науч. конф. - СПб.: Изд-во Политехн. ун-та, 2015. - С. 64-67.

14. Колесникова И.Л., Долгина О.А. Англо-русский терминологический справочник по методике преподавания иностранных языков: справ. пособие. - М.: Дрофа, 2008. - 431 с.

15. Аракин В.Д. Практический курс английского языка. 3 курс: учебник для студ. вузов. - М.: ВЛАДОС, 2006. - 431 с.

\section{References}

1. Zimnjaja I.A. Kompetencija i kompetentnostnost' v ramkah kompetentnostnogo podhoda $\mathrm{v}$ obrazovanii [Competence and competency in the framework of the competencebased approach in education]. Inostrannye jazyki v shkole, 2012, no. 6, pp. 25-27.

2. Biboletova M.Z., Trubaneva N.N. Programma kursa anglijskogo jazyka "Enjoy English" dlja uchashhihsja 2-9 klassov obshheobrazovatel'nyh uchrezhdenij Rossii [An English language course syllabus "Enjoy English" for the pupils of the 2-9 forms of Russian public schools]. Moscow: Titul Publ., 2006.

3. Safonova V.V. Sociokul'turnyj podhod k obucheniju inostrannym jazykam kak special'nosti [Socio-cultural approach to teaching foreign languages to linguists]. Thesis of the Doctor of Pedagogics. Moscow, 1993. $47 \mathrm{p}$.

4. Safonova V.V. Kommunikativnaja kompetencija: sovremennye podhody $\mathrm{k}$ mnogourovnevomu opisaniju $\mathrm{v}$ metodicheskih celjah [Communicative competence: contemporary approaches to multilevel description for the purpose of teaching methods development]. Moscow: Evroshkola Publ., 2004.

5. Hymes D.H. On Communicative Competence. Sociolinguistics. Selected Readings. Harmondsworth: Penguin, 1972, pp. 269-293. 
6. Bachman L.F. Fundamental Considerations in Language Testing. Oxford, OUP, 1990. $408 \mathrm{p}$.

7. Van Ek J. Objectives for foreign language learning. Vol. 2: Levels. Strasbourg: Council of Europe, 1987.99 p.

8. Gejhman L.K. Interaktivnoe obuchenie obshheniju (obshhepedagogicheskij podhod) [Interactive teaching communication (general pedagogic approach)]. Thesis of the Doctor of Pedagogics. Yekaterinburg, 2003. $426 \mathrm{p}$.

9. Federal'nyj gosudarstvennyj obrazovatel'nyj standart vysshego obrazovanija po napravleniju podgotovki 45.03.02 «Lingvistika» (uroven' bakalavriata). Federal state educational standard of higher education for the major 45.03.02 Linguistics (Bachelor's degree). Available at: http://www.mshu.edu.ru/files/UMU/standarts/45.03.02_lingvis-tika.pdf (accessed 14 October 2015).

10. Shevc I.A. Rolevye igry kak sredstvo povyshenija jeffektivnosti obuchenija inostrannomu jazyku [Role plays as means to enhance efficiency in foreign language teaching]. Jekonomicheskie, juridicheskie $i$ sociokul'turnye aspekty razvitija regionov. Cheljabinsk: Izd-vo ChIJeP im. M.V. Ladoshina, 2008, pp. 264-272.

11. Solovova E.N. Metodika obuchenija inostrannym jazykam: bazovyj kurs lekcij [Foreign language teaching methods: basic course of lectures]. Moscow: Prosveshhenie Publ., 2005. 239 p.

12. Leont'ev A.A. Pedagogicheskoe obshhenie [Pedagogical communication]. Moscow: Prosveshhenie Publ., 1980. 214 p.

13. Gejhman L.K., Stavceva I.V. Innovacionnoe obrazovanie: sinergija tehnologii i tvorchestva [Innovations in education: technology and creativity synergy]. Materialy mezhdunarodnoj nauchnoj konferencii "Kommunikacija v polikodovom prostranstve: lingvokul'turologicheskie, didakticheskie, cennostnye aspekty" [Proc. Int. Sci. Conf. "Communication in polycode environment: Linguocultural, didactic, axiological aspects"]. Saint-Petersburg: Izd-vo Politehn. un-ta, 2015, pp. 64-67.

14. Kolesnikova I.L., Dolgina O.A. Anglo-russkij terminologicheskij spravochnik po metodike prepodavanija inostrannyh jazykov [English-Russian terminology reference book in foreign language teaching methods]. Moscow: Drofa Publ., 2008. 431 p.

15. Arakin V.D. Prakticheskij kurs anglijskogo jazyka. 3 kurs: uchebnik dlja stud. Vuzov [Practical course of the English language: for the third year students]. Moscow: VLADOS Publ., 2006. 431 p. 


\section{Сведения об авторе}

\section{СТАВЦЕВА Ирина Вячеславовна}

e-mail: i.v.stavtseva@gmail.com

Кандидат педагогических наук, доцент кафедры лингвистики и межкультурной коммуникации, Южно-Уральский государственный университет (НИУ) (Челябинск, Россия)

\section{ЕРОХИНА Екатерина Павловна}

e-mail: all_the_right_faces@mail.ru

Магистрант, направление «Лингвистика», профиль «Перевод и переводоведение», Челябинский государственный университет (Челябинск, Россия)

\section{About the author \\ Irina V. STAVTSEVA \\ e-mail: i.v.stavtseva@gmail.com}

Candidate of Pedagogics, Associate Professor, Department of Linguistics and Cross-Cultural Communication, South Ural State University (National Research University) (Chelyabinsk, Russia)

\section{Ekaterina P. Erokhina}

e-mail:all_the_right_faces@mail.ru

Master's Degree Student, major: Lingustics (profile: Translation and Translation Studies), Chelyabinsk State University (Chelyabinsk, Russia) 